\title{
Feições erosivas na bacia do córrego do Espraiado, São Pedro (SP), seus tipos e evolução entre 1972-2002
}

\author{
Lazaro Valentin Zuquette ${ }^{1}$, José Alcino Rodrigues Carvalho ${ }^{2} \&$ \\ Gisele Ribeiro de Barros Yamanouth ${ }^{3}$
}

\begin{abstract}
Resumo O presente artigo apresenta os resultados do estudo dos fenômenos de erosão na área da bacia do córrego do Espraiado, localizada a NE da cidade de São Pedro (São Paulo, Brasil). Este estudo insere-se num programa de investigação que tem por objetivo a preparação do mapa geotécnico daquela área. É apresentada a caracterização sumária da zona (clima, vegetação, geomorfologia e geologia), bem como o mapa de material inconsolidado preparado durante o estudo. Chama-se a atenção para o processo de erosão pluvial que constitui o maior problema ambiental da área. É investigada a evolução do processo erosivo ao longo de 30 anos, com base em observações realizadas em quatro situações temporais diferentes: 1972, 1978, 1995 e 2002. Finalmente, é evidenciada a influência que a ação antrópica tem no deflagrar daquele processo ou no acelerar da sua evolução.
\end{abstract}

Palavras-chave: Erosão, mapeamento geotécnico, Brasil.

\begin{abstract}
Erosion processes in the córrego do Espraiado watershed, São Pedro (SP), types and evolution between 1972 - 2002. This paper presents the results of the study of the erosion phenomena in the córrego do Espraiado basin, located NE of the city of São Pedro (São Paulo). This study belongs to an investigation programme, which aims the preparation of the engineering geological map of that area. A brief characterization of the area (climatic conditions, vegetation, geomorphology and geology) and the map of unconsolidated materials are presented. Attention is drawn to the water erosion process, which is the main environmental problem in the area. The evolution of the water erosion process along 30 years is investigated based upon the data registered in four distinct temporal situations: 1972, 1978, 1995 and 2002. Finally, the influence of the anthropic action in that respects triggering or accelerating the evolution of that process is pointed out.
\end{abstract}

Keywords: Erosion, engineering geological mapping, Brazil.

INTRODUÇÃO A erosão pluvial é um processo erosivo originado pela água da chuva em que as forças devidas ao escoamento superficial e subsuperficial que se instalam em função de um episódio de precipitação são capazes de proceder ao arranque e arraste das partículas do solo.

Estes processos erosivos são freqüentemente desencadeados ou acelerados devido ao incorreto uso do solo tal como culturas inadequadas ou intensivas, atividades de desmatamento ou outras intervenções antrópicas que levam à degradação do solo.

Degradação pode ser indicada como o conjunto de processos resultantes de danos ao meio ambiente, pelos quais se perdem ou se reduzem algumas de suas propriedades, tais como a qualidade ou capacidade produtiva dos recursos ambientais (Decreto Federal 97.632/89).

Segundo a norma brasileira ABNT-NBR 10 703 (1989), área degradada é toda aquela cujo solo sofreu processo de degradação, e solo degradado é definido como a alteração adversa das características do solo em relação aos seus diversos usos possíveis, tanto os estabelecidos em planejamento quanto os potenciais.

Segundo Blum (1997), o termo degradação do solo (soil degradation) é usado para descrever a deterioração do solo causada por diferentes formas de uso. Para Lal (1990) significa a perda de produtividade atual ou potencial bem como a utilidade. Johnson et al. (1997 in Dias, 2001), consideram que seja qualquer alteração ou distúrbio ao solo detectado como deletério ou indesejável. Uma forma de degradação é a perda do próprio solo ocasionada pela erosão.

Existem duas condições a atender quanto ao fenômeno erosão dos solos: por um lado a erosividade da chuva na dependência da sua intensidade e duração; por outro, a erodibilidade do solo, dependente de vários fatores tais como as características físicas e mecânicas, a morfologia e tipo de uso.

No Brasil existem vastas regiões sujeitas a intensa erosão pluvial. A bacia do córrego do Espraiado, nas proximidades da cidade de São Pedro (SP) está sujeita aos intensos fenômenos deste tipo os quais têm acarretado o desaparecimento de quantidades significativas de solo arável e a instalação de feições erosi- 
vas típicas designadas por voçorocas. Tratando-se de fenômenos de difícil reversibilidade é importante evitálos ou, quando tal não é possível, impõe-se tentar reter o seu avanço minimizando, portanto os seus nefastos efeitos.

São conhecidos estudos relativos aos processos erosivos na região de São Pedro, tais como: Santoro (1991) que estudou os fenômenos erosivos acelerados como os que ocorrem no córrego Tucum; IPT (1991, 1993) que identificou e cadastrou as principais feições erosivas da região; Pejon (1992) elaborou o mapeamento geotécnico voltado para os processos erosivos na folha de Piracicaba; Fancicani (1995a, 1995b) estudou a influência da estruturas tectônicas no desenvolvimento de voçorocas e sugeriu propostas para reabilitação dessas áreas degradas, assim como levantou aspectos jurídicos e institucionais relacionados com este problema ambiental.

O presente artigo surge como resultado parcial de uma investigação que vem sendo conduzida na Escola de Engenharia de São Carlos (USP) objetivando o conhecimento das características dos terrenos daquela bacia por forma a possibilitar a seleção das medidas de preservação e corretivas dos referidos fenômenos erosivos. Ele trata das características das feições erosivas que se instalam nos terrenos da bacia bem como da sua evolução entre 1972 e 2002 e dá conta da influência antrópica nesse processo.

\section{CARACTERÍSTICAS SUMÁRIAS DA ÁREA}

Localização, Clima e Vegetação A bacia do córrego do Espraiado abrange uma área de cerca $12 \mathrm{~km}^{2}$ a nordeste da cidade de São Pedro, no Estado de São Paulo (Fig. 1). O córrego do Espraiado nasce a norte de São Pedro, tem uma extensão próxima de $8 \mathrm{~km}$, com direção NW-SE e deságua no Ribeirão Aragua. Os canais de drenagem são de média a baixa densidade, com padrões subdentríticos.

De acordo com a classificação de Köppen (1948) o clima predominante enquadra-se no tipo Cwa, representando clima úmido e quente com Inverno seco (Pejon, 1992), e precipitação média anual de $1200 \mathrm{~mm}$ (Pejon \& Zuquette, 2001). As temperaturas médias do mês mais quente são de aproximadamente $22^{\circ} \mathrm{C}$, e as do mês mais frio inferiores a $18^{\circ} \mathrm{C}$. O clima pode ser designado subtropical (Setzer 1966 in Pejon op. cit).

A cobertura vegetal é bem diversificada, constituída por vegetação nativa, reflorestamento por eucaliptos e pinus, cana-de-açúcar, pastagens, e mata ciliar ao longo das margens do córrego. A vegetação original (mata latifoliada) encontra-se em grande parte substituída por pastagens, cana-de-açúcar e reflorestamento (eucalipto), mas é possível observá-la ainda em locais restritos, como nas áreas de drenagem e na parte superior de algumas encostas.

Geomorfologia e Geologia O córrego do Espraiado estende-se na direção noroeste-sudeste. Em geral o vale é aberto em forma de U, com exceção da cabeceira, onde é fechado e encaixado. Ao longo do córrego há

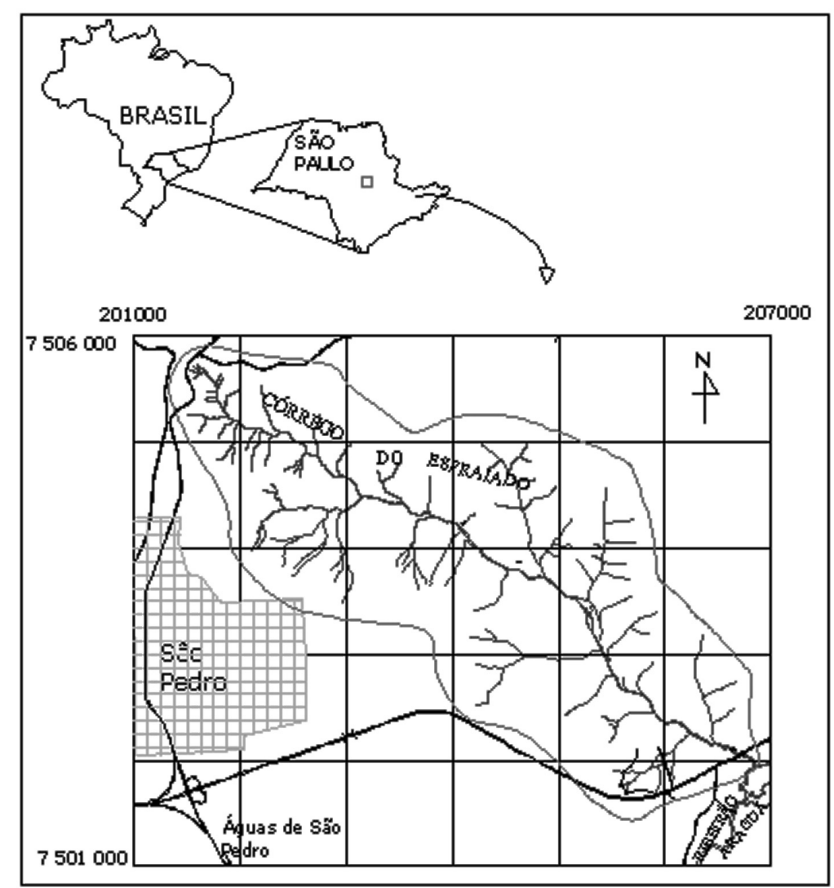

Figura 1- Localização da bacia do córrego do Espraiado.

a presença de terraços, compondo a planície aluvionar. As encostas da margem esquerda são côncavas na parte superior e convexas na parte intermédia-inferior. As encostas da margem direita são geralmente retilíneas na sua parte superior e côncavas no terço intermédioinferior e são as que apresentam mais feições erosivas.

A bacia do Espraiado tem como substrato rochoso a Formação Pirambóia, de idade triássico-jurássica, pertencente à Bacia Sedimentar do Paraná. Esta formação é constituída essencialmente por arenitos de grão médio a fino, de cor vermelha, branca e amarela. As estruturas predominantes são estratificações cruzadas de pequeno a médio porte, com intercalações de material com maior quantidade de finos e outras de areia, que se encontram nas áreas mais altas, e estratificações plano - paralelas que se localizam nas zonas mais baixas.

Problemas Ambientais Os principais problemas ambientais identificados na área da bacia do Espraiado são o assoreamento do leito do rio e feições erosivas marginais intensas ao longo do rio, efeitos negativos decorrentes da exploração inadequada de areia em três locais de extração e a presença de varias feições erosivas, principalmente voçorocas.

As voçorocas, também chamadas boçorocas, são feições erosivas típicas de regiões de clima tropical e subtropical, como o Brasil, onde este tipo de feição é comum, gerando um grande problema ambiental associado à degradação do solo. São formas de ravinamento ocasionadas pela articulação entre erosão originada por escoamento d'água superficial concentrado e subsuperficial, com erosão interna (piping). Desenvolvem-se por deslizamento lateral de paredes (auxiliado por sub- 
pressões em trincas de descompressão) e erosão remontante, por vezes com abatimentos súbitos de terreno (Santoro, 1991; Ponçano \& Prandini, 1987). De acordo com Iwasa \& Prandini (1980), as voçorocas em áreas rurais desenvolvem-se geralmente em pastagens e em solos de culturas com má cobertura, sujeitas a manejo inadequado; na maioria das vezes o ravinamento é iniciado ao longo de valas de demarcação, trilhas de linhas de plantio e, quando a ravina intercepta o lençol freático, transforma numa voçoroca típica. Segundo esses autores a mudança do regime de escoamento, devido ao desmatamento, permite uma maior velocidade do escoamento da água pluvial já que diminuem os obstáculos e estruturas retentoras de água.

Segundo Ridente Júnior (2000), nesta feição de erosão há transporte muito intenso de sedimentos devido ao escoamento superficial e a ocorrência de piping. As boçorocas são consideradas de grande porte quando têm largura superior a $5 \mathrm{~m}$, e profundidade superior a $2 \mathrm{~m}$, as bordas são abruptas, com ruptura instável da superfície do terreno.

As feições erosivas de grande porte identificadas na bacia do Espraiado e designadas voçorocas neste trabalho foram deflagradas e desenvolveram-se devido apenas a escoamento superficial. Elas não interceptaram o nível freático, condição considerada pos alguns autores, como atrás ficou dito, para atribuição daquela denominação. O tamanho das feições, porém, não é adequado enquadrá-las em designações de menor dimensão como o tipo ravinas.

Considera-se, pois, que o porte ou tamanho das feições deve prevalecer independentemente de atingirem ou não o nível freático. Julga-se mais adequado designar por voçorocas aquelas feições cuja recuperação não possa ser conseguida através da utilização de técnicas e meios mecânicos usuais de manejo da terra.

MÉTODOS Nos anos 90 o mapeamento geotécnico voltou-se para os aspectos ambientais, buscando uma melhor compreensão dos processos geológicos/antrópicos e o relacionamento como o meio físico (Kopezinski, 1998).

Segundo Zuquette \& Nakazawa (1998) as cartas geotécnicas são instrumentos de aplicação que devem expressar os diferentes comportamentos/desempenhos esperados do terreno, diante de usos do solo prédeterminados, através de uma compartimentação em zonas ou unidades geotécnicas, cada qual com orientações técnicas preventivas e corretivas dos problemas característicos, previamente identificados.

Um dos problemas objeto de tratamento pela cartografia geotécnica é exatamente o da erosão, nomeadamente através da preparação dos mapas de susceptibilidade à erosão (Rodrigues-Carvalho et al., 2004). Nestes mapas, com base nas características físicas, geotécnicas e morfológicas do terreno, e ainda, com base no inventario das feições de erosão presentes, são definidas zonas com diferentes predisposições à erosão.

Para a realização da investigação na área da bacia do córrego do Espraiado, foi adotada a metodologia de Zuquette (1997) que tem por base um conjunto de procedimentos que buscam refletir as verdadeiras condições do meio físico e, a partir dos dados obtidos, possam ser expressos através de mapas e /ou cartas.

No âmbito daquela investigação foram elaborados somente os documentos fundamentais básicos, que são documentos que registram as características dos componentes do meio físico, por meio da variação espacial dos atributos, pois estes documentos foram considerados adequados para o entendimento dos processos erosivos atuantes na área da bacia e para fazer uma analise critica das técnicas utilizadas para o controle e reabilitação de áreas afetadas por feições erosivas.

A figura 2 mostra o fluxograma das atividades e documentos obtidos neste trabalho.

MAPA DE MATERIAL INCONSOLIDADO As unidades de materiais inconsolidados foram classificadas quanto a sua gênese e textura. Quanto à gênese os materiais foram classificados como residuais, quando os solos são produtos da alteração in situ do substrato rochoso, e materiais retrabalhados, quando os materiais inconsolidados são oriundos de outros lugares. A classificação da textura baseou-se nos ensaios granulométricos.

Na tabela 1 apresentam-se os intervalos de valores obtidos nos ensaios granulométricos para os materiais inconsolidados residuais (12 ensaios) e retrabalhados (18 ensaios), em termos de percentagens de argila, silte areia fina, areia media e areia grossa. A tabela 2 apresenta a descrição do perfil de alteração adotado no trabalho.

Os materiais inconsolidados foram inicialmente classificados em 21 unidades, compreendendo solo residual ( $R s 01$ a $R s 00)$, solo saprolítico ( $R s p 01)$, rocha muito alterada (Ram01a a Ram03), rocha pouca alterada (Rap01 e Rap02), materiais retrabalhados (Rt01 a $R t 08)$, aluvião $(A l)$, e ainda material de aterro.

Para fins de preparação do mapa de material inconsolidado aquelas unidades foram agregadas em 16 unidades cartográficas tal como se apresenta na tabela 3 onde consta também a área ocupada por cada uma e a sua representatividade em termos de percentagem da área da bacia. O mapa de material inconsolidado é apresentado na figura 3 . É de notar que a percentagem total de rocha sã, pouco alterada e muito alterada é significativa face à percentagem total de material inconsolidado, quer residual quer retrabalhado. Os seus principais afloramentos são nas escarpas e em encostas retilíneas íngremes.

\section{ERODIBILIDADE DO MATERIAL INCONSOLI-}

DADO Vários autores têm desenvolvido investigação no âmbito dos fenômenos de erosão e propuseram métodos para a avaliação da erodibilidade dos solos. Os diferentes métodos podem dividir-se em indiretos, e.g. Wishmeier et al. (1971), método MCT (Vertamatti \& Araujo) (1990), índice Bouyoucos (Morgan, 1986) e diretos e.g. ensaio de Inderbitzen (Santos \& Mershmann, 2001), absorção de água e perda de peso por imersão 


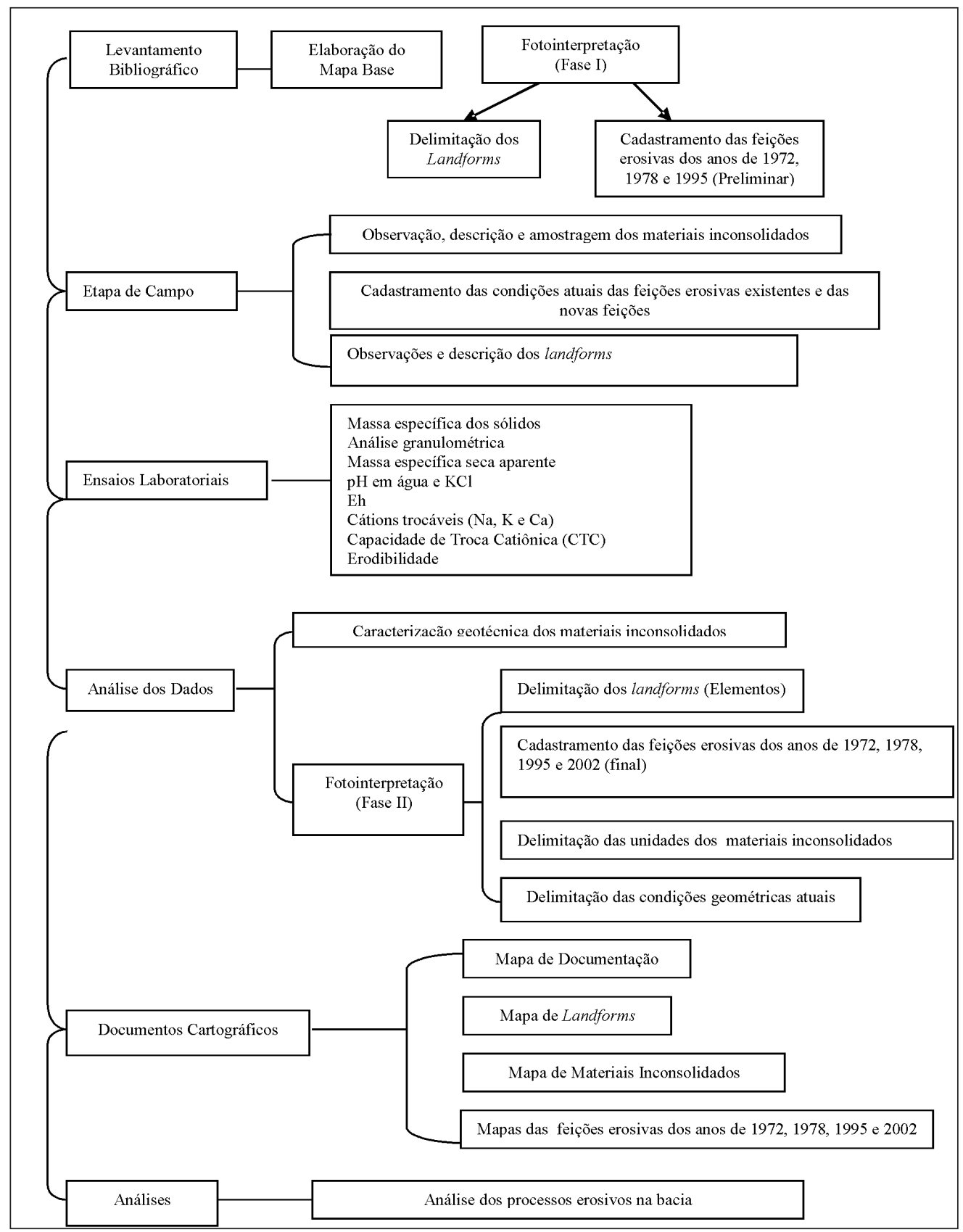

Figura 2 - Fluxograma das atividades e documentos obtidos.

(Nogami \& Villibor, 1979), ensaio de Pinhole (Silva \& Lacerda, 2001), ensaio com o cilindro rotativo, etc.

O índice de erodibilidade proposto por Nogami \& Villibor (opus cit.) tem sido aplicado no estudo de erosão de solos no Brasil e apresenta as vantagens de ser rápido, de fácil execução e não requerer equipamento sofisticado (Pejon, 1992). Devido às vantagens que o método oferece é útil na identificação dos materiais que tendem a apresentar problemas de erosão e pode ser utilizado nos mapeamentos geotécnicos. Aquele autor aplicou este método para a determinação do índice de erodibilidade dos materiais inconsolidados e obteve resultados satisfatórios, pois o método permitiu a identificação de $90 \%$ dos materiais erodíveis, mas acrescentou que o índice não é uma medida quantitativa do potencial à erosão, mas sim um índice qualitativo para estimar a erodibilidade dos materiais inconsolidados em mapeamentos geotécnicos, não devendo ser usado diretamente em obras.

O índice de erodibilidade proposto por Nogami \& Villibor (1979) é calculado através da seguinte expressão: $\mathrm{E}=52 \mathrm{~S} / \mathrm{P}$ sendo $\mathrm{S}$ o índice de absorção de água e $\mathrm{P}$ a perda de peso por imersão em 24 horas, determinações feitas em amostras indeformadas. No entanto, segundo Pejon (opus cit.) o índice de erodibilidade calculado através de $\mathrm{E}=40 \mathrm{~S} / \mathrm{P}$ ajusta-se melhor às condições de erodibilidade da bacia em estudo.

O índice de absorção (S) é estabelecido com o auxílio de um gráfico que representa o volume de água absorvido por unidade de área da base do corpo de prova (q) em função da raiz quarada do tempo $(\sqrt{t})$, sendo 
Tabela 1- Frações argila, silte e areia nos materiais residuais e retrabalhados.

\begin{tabular}{l|c|c|c|c|c|c}
\hline $\begin{array}{l}\text { Tipo } \\
\text { de material }\end{array}$ & \% Argila & \% Silte & \% Areia fina & \% Areia media & $\begin{array}{c}\text { \% areia } \\
\text { grossa }\end{array}$ & $\begin{array}{c}\% \text { total de } \\
\text { areia }\end{array}$ \\
\hline Inconsolidados & $3,6-15,0$ & $1,0-5,0$ & $27,0-50,6$ & $29,5-55,6$ & $0-5,8$ & \\
residuais & Média: 8,4 & Média: 2,4 & Média: 39,7 & Média: 46,7 & Média: 1,8 & 88,2 \\
\hline Inconsolidados & $8,2-20,8$ & $1,3-5,2$ & $24,2-51,3$ & $27,7-54,2$ & $0,5-8,1$ & \\
retrabalhados & Média: & Média: & Média: & Média: & Média: & 84,4 \\
\hline
\end{tabular}

Tabela 2 - Descrição do perfil de alteração adotado neste trabalho.

\begin{tabular}{l|c|l}
\hline Níveis de Alteração & Identificação & Descrição \\
\hline Solo residual & Rs & $\begin{array}{l}\text { Rocha totalmente transformada em solo, não há presença de } \\
\text { estruturas e textura primárias. }\end{array}$ \\
\hline Solo saprolítico & Rsp & Ainda ocorre cerca de 10\% de rocha alterada imersa no solo. \\
\hline Rocha muito alterada & Ram & $\begin{array}{l}\text { Preservação das estruturas primárias, descoloração, e baixa } \\
\text { resistência à desagregação. }\end{array}$ \\
\hline Rocha pouco alterada & Rap & $\begin{array}{l}\text { Preservação das estruturas primárias, pouca descoloração, e alta } \\
\text { resistência à desagregação. }\end{array}$ \\
\hline Rocha sã & Rsa & Rocha com poucos sinais de alteração. \\
\hline
\end{tabular}

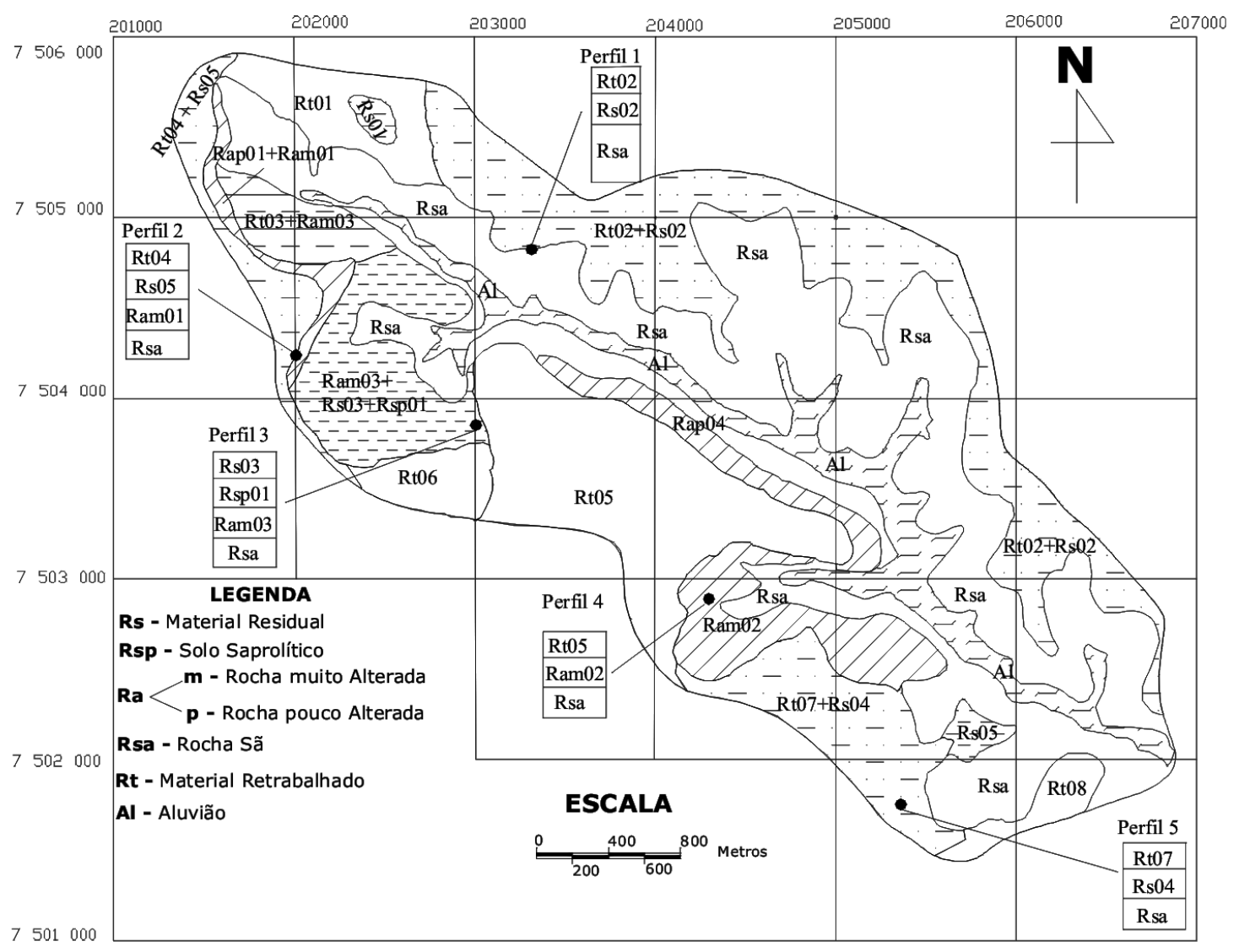

Figura 3 - Mapa de material inconsolidado.

o índice de absorção $(\mathrm{S})$ o coeficiente angular do trecho inicial retilíneo. Concluído o ensaio de absorção, reali- za-se o ensaio de perda por um período de 24 horas, determinando-se assim a perda de massa seca $(\mathrm{P})$ em 
Tabela 3 - Unidades e áreas de materiais inconsolidados.

\begin{tabular}{l|c|c}
\hline Unidades & Área $\left(\mathrm{m}^{2}\right)$ & Área (\%) \\
\hline Rs01 & 45808,98 & 0,37 \\
\hline Rs02 + Rt02 & 1969437,32 & 15,82 \\
\hline Rs03 + Ram03+ Rsp01 & 730625,49 & 5,87 \\
\hline Rs04 + Rt07 & 655131,35 & 5,26 \\
\hline Rs04 & 69858,28 & 0,56 \\
\hline Rs05+Rt04 & 343403,29 & 2,76 \\
\hline Ram02 & 545588,54 & 4,38 \\
\hline Rt03+Ram03 & 278247,38 & 2,23 \\
\hline Rap01+Ram01 & 151861,59 & 1,22 \\
\hline Rap02 & 274311,16 & 2,20 \\
\hline Rsa & 4157372,38 & 33,39 \\
\hline Rt01 & 453644,07 & 3,64 \\
\hline Rt05 & 1431152,63 & 11,50 \\
\hline Rt06 & 228227,62 & 1,83 \\
\hline Rt08 & 168524,35 & 1,35 \\
\hline Al & 946979,22 & 7,61 \\
\hline Total & 12450173,66 & 100,00 \\
\hline
\end{tabular}

percentagem em relação à massa seca inicial da amostra. O valor de E igual a 1, separa os materiais erodíveis dos não erodíveis; valores menores que 1 indicam solos com alta erodibilidade.

$\mathrm{O}$ índice de erodibilidade $\mathrm{E}$ foi calculado para as unidades de materiais inconsolidados cartografados na área da bacia do córrego do Espraiado e os resul- tados foram coerentes com as observações de campo. As figuras 4 e 5 dão conta dos resultados obtidos para o caso dos materiais inconsolidados residuais e para o caso dos materiais inconsolidados retrabalhados.

No caso dos materiais retrabalhados ocorrem alguns valores anômalos cujas razões foram indagadas tendo-se concluído que a maior exposição solar das feições onde foram colhidas as amostras bem como a presença de raízes nas mesmas são fatores a ter em conta para a explicação daqueles valores.

FEIÇÕES EROSIVAS NA BACIA Uma das partes do trabalho consistiu no cadastro e mapeamento das feições erosivas na área da bacia em quatro situações temporais distinta: 1972, 1978, 1995 e 2002. Os mapas que refletem a situação naquelas três primeiras datas foram derivados da analise das fotografias aéreas obtidas naqueles anos. $\mathrm{O}$ mapa correspondente à situação em 2002 foi preparado a partir de observações no terreno, nesse ano, anotando-se as feições não registradas nas fotografias de 1995.

Os principais tipos de feições erosivas cadastradas foram sulcos, ravinas e voçorocas. Por vezes estas feições surgem em associação e para os objetivos de cadastro foram considerados quatro tipos: concentração de sulcos $(\mathrm{C})$, ravinas $(\mathrm{R})$, concentração de sulcos e ravinas (CR), voçorocas $(\mathrm{V})$, e ocorrência de voçorocas e ravinas (VR).

Tendo em atenção os objetivos mais alargados do trabalho final, as feições erosivas foram cadastradas quanto ao tipo de feição, suas características, localização, unidade de material inconsolidado, de landform, uso do solo na qual estão inseridas, e observações importantes de cada feição. Na preparação dos mapas de

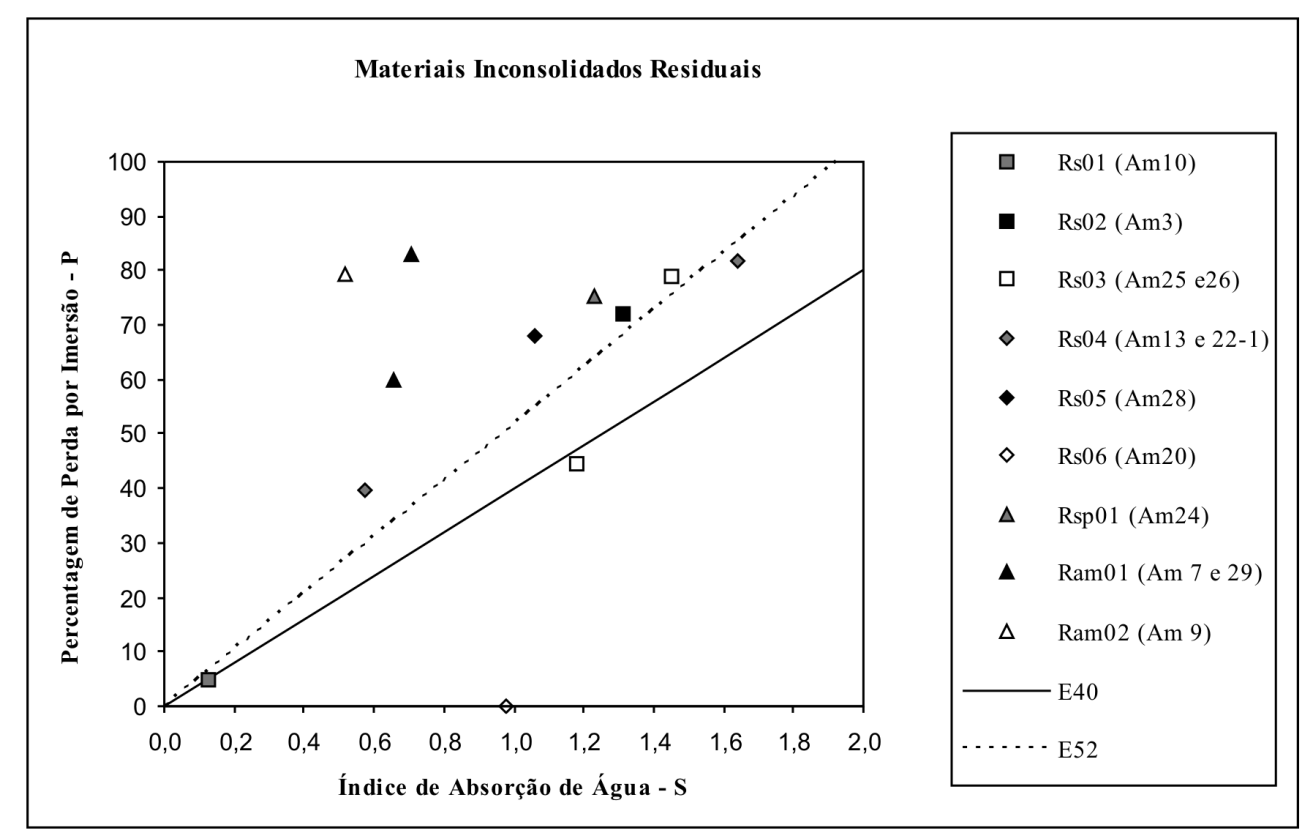

Figura 4 - Diagrama de índice de absorção de água (S) versus percentagem de perda por imersão $(P)$ dos materiais inconsolidados residuais com a identificação das amostras de cada unidade. 


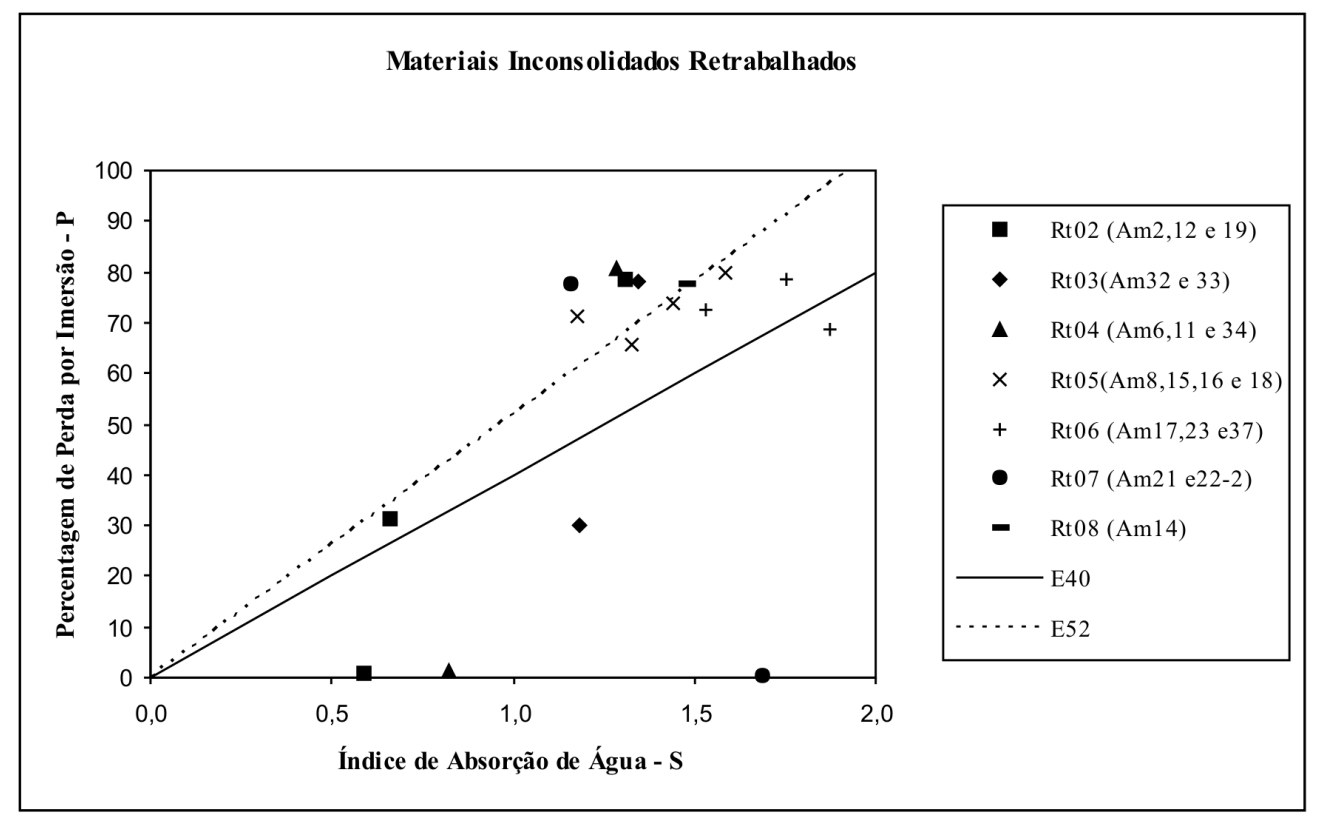

Figura 5 - Diagrama de índice de absorção de água (S) versus percentagem de perda por imersão $(P)$ dos materiais inconsolidados retrabalhados, com a identificação das amostras de cada unidade.

cadastro, para as feições erosivas ocorrentes no ano de 1972 utilizaram-se números, por exemplo, 01V; paras as do ano 1978, algarismos romanos como IV; para as do ano de 1995, letras minúsculas, como aV; e para 2002, letras gregas, como $\alpha \mathrm{V}$.

ANÁLISE DE RESULTADOS A análise do cadastro geral elaborado das feições erosivas se encontra na tabela 4 e nas figuras $6,7,8$ e 9 , as feições referentes aos anos de 1972, 1978, 1995 e 2002, respectivamente, o que permite extrair os resultados que a seguir se apresentam.

Situação de Partida, 1972 A figura 6 mostra o mapa das feições erosivas do ano de 1972. Nesta data, as feições erosivas cadastradas localizavam-se nas cabeceiras de drenagens, num intervalo de declividade de $10-50 \%$. Os principais tipos de encostas onde estas estavam inseridas eram encostas retilíneas, íngreme-retilíneas, retilíneas-retilíneas, retilíneas-côncavas, côncavas-

Tabela 4 - Resultado geral do cadastro das feições erosivas.

\begin{tabular}{l|c|c|c|c}
\hline $\begin{array}{l}\text { Anos } \\
\text { Feições erosivas }\end{array}$ & 1972 & 1978 & 1995 & 2002 \\
\hline Concentração de sulcos & 04 & 04 & 01 & 01 \\
\hline Ravinas & 25 & 25 & 10 & 10 \\
\hline Voçorocas & 17 & 15 & 28 & 30 \\
\hline Concentração de sulcos e Ravinas & 02 & - & - & - \\
\hline Voçorocas e Ravinas & - & 04 & 05 & 05 \\
\hline Total & 49 & 48 & 44 & 46 \\
\hline
\end{tabular}

côncavas, e côncavas-convexas. A maioria das feições erosivas identificadas foi do tipo ravina, num total de 25 , tendo sido identificadas 17 voçorocas. Verificou-se que tanto os residuais como os retrabalhados são materiais arenosos com baixa resistência a erosão. Mesmo nas rochas muito e pouco alterada do arenito Pirambóia há registro de feição erosiva.

Situação em 1978 A figura 7 representa o Mapa de registro das Feições Erosivas no ano de 1978. Em relação ao cadastramento de 1972, as feições evoluíram principalmente para voçorocas, como a 11, 14, 15, 22, 23 e 28, que em 1972 eram ravinas. A feição 25, que era uma concentração de sulcos e ravinas, passou a ser identificada como ocorrência de voçorocas e ravinas. As feições 38 e 39 que eram voçorocas, evoluíram e tornaram-se maiores. As voçorocas 45 e 46 evoluíram e uniram-se, formando uma voçoroca de grande porte, ramificada. As ravinas 9, 12, 42 e 43 foram de alguma forma recuperadas, provavelmente por aterramento.

No ano de 1978, foram cadastradas 10 novas feições, sendo 9 ravinas e 1 concentração de sulcos, localizadas em encostas intermediárias e cabeceiras de drenagem. Praticamente todas as novas feições se encontravam em encostas retilíneas íngremes, retilíneascôncavas, e retilíneas- -convexas. Verifica-se, pois, um aumento muito significativo dos processos erosivos ao longo de seis anos, entre 1972 e 1978, pelo aparecimento de novas feições erosivas, mas também pela evolução de feições menos avançadas para mais avançadas de erosão (concentração de sulcos e ravinas para voçorocas).

Situação em 1995 A figura 8 mostra o mapa de feições erosivas identificadas em 1995. No cadastro deste 


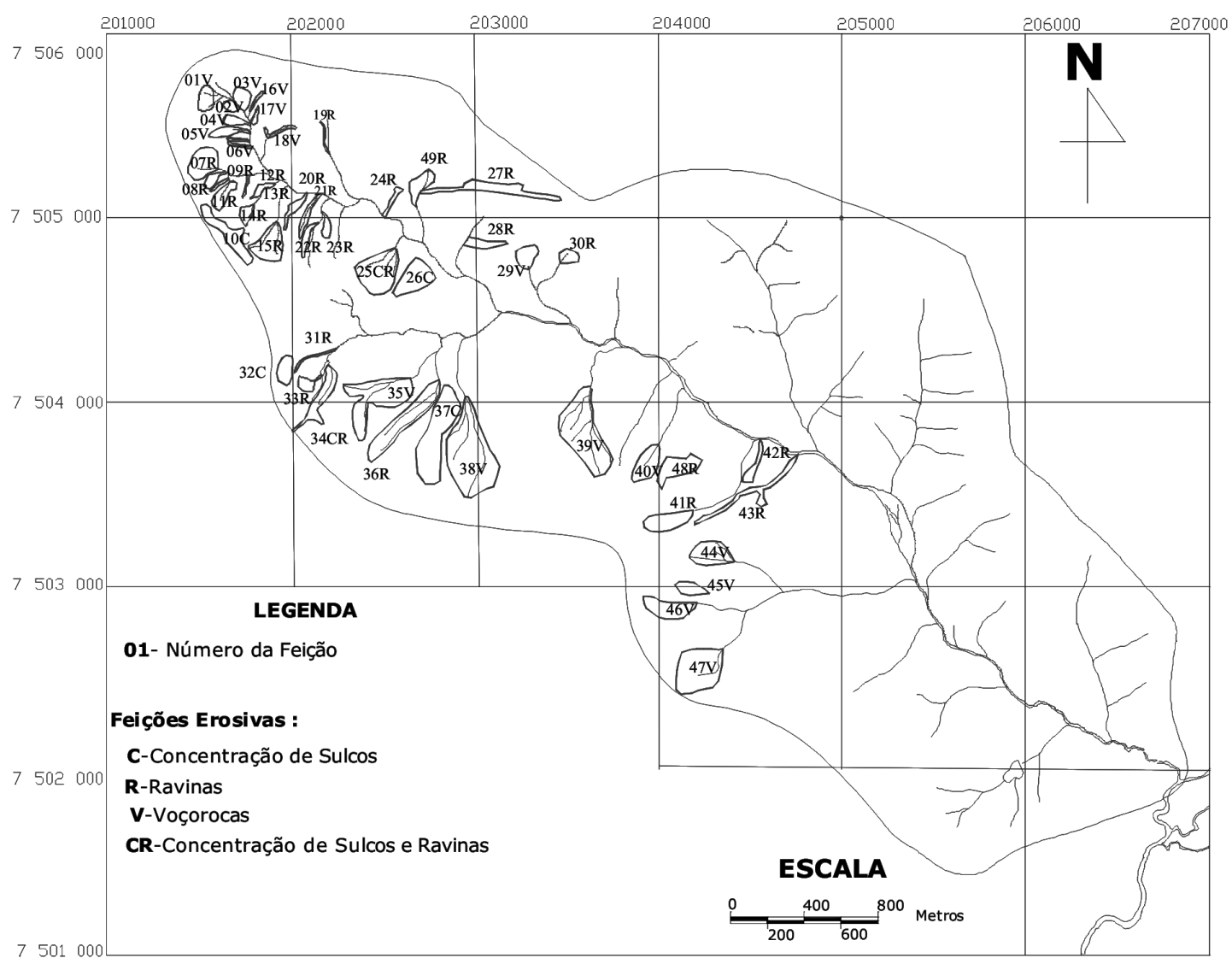

Figura 6 - Mapa das feições erosivas do ano de 1972.

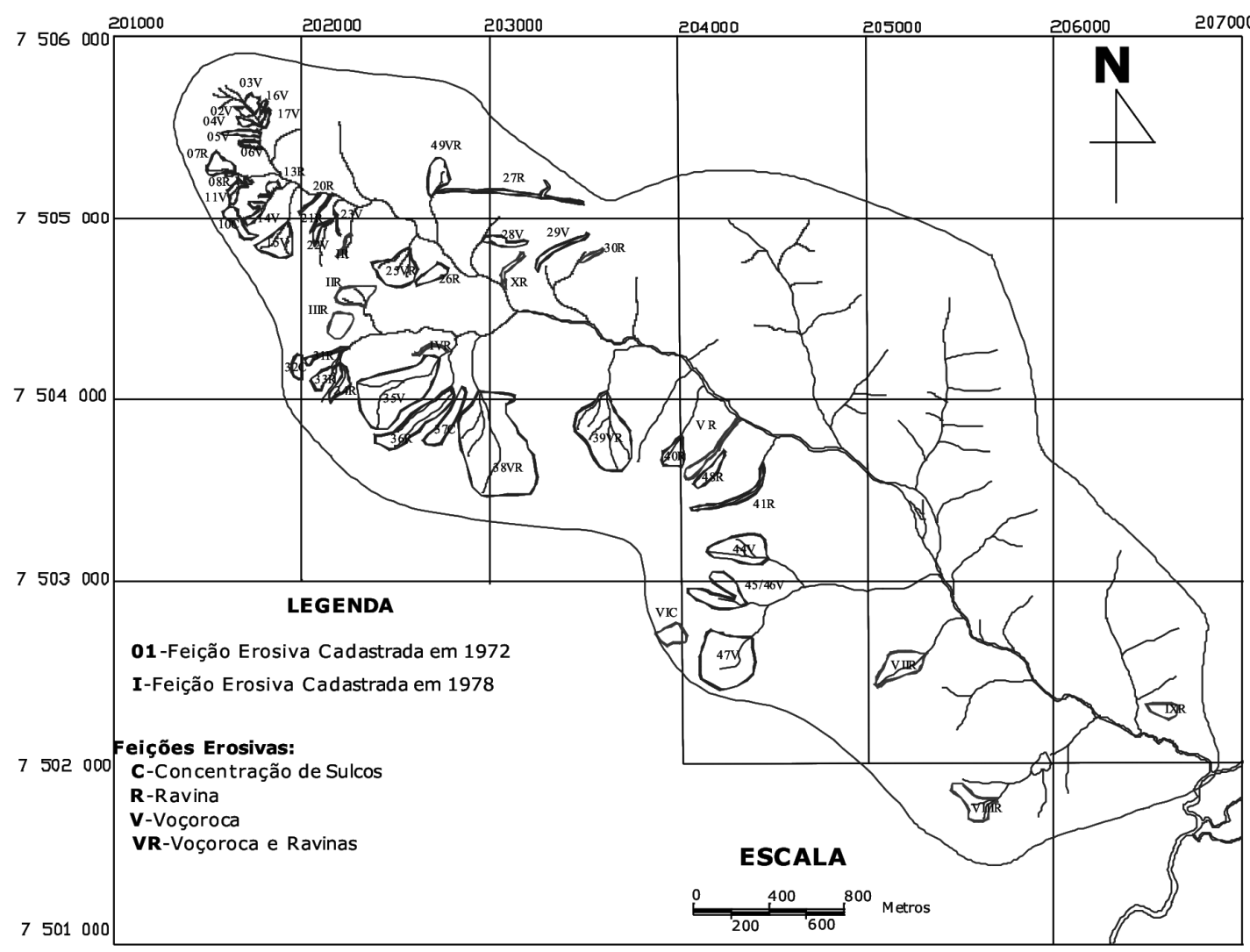

Figura 7 - Mapa das feições erosivas do ano de 1978. 


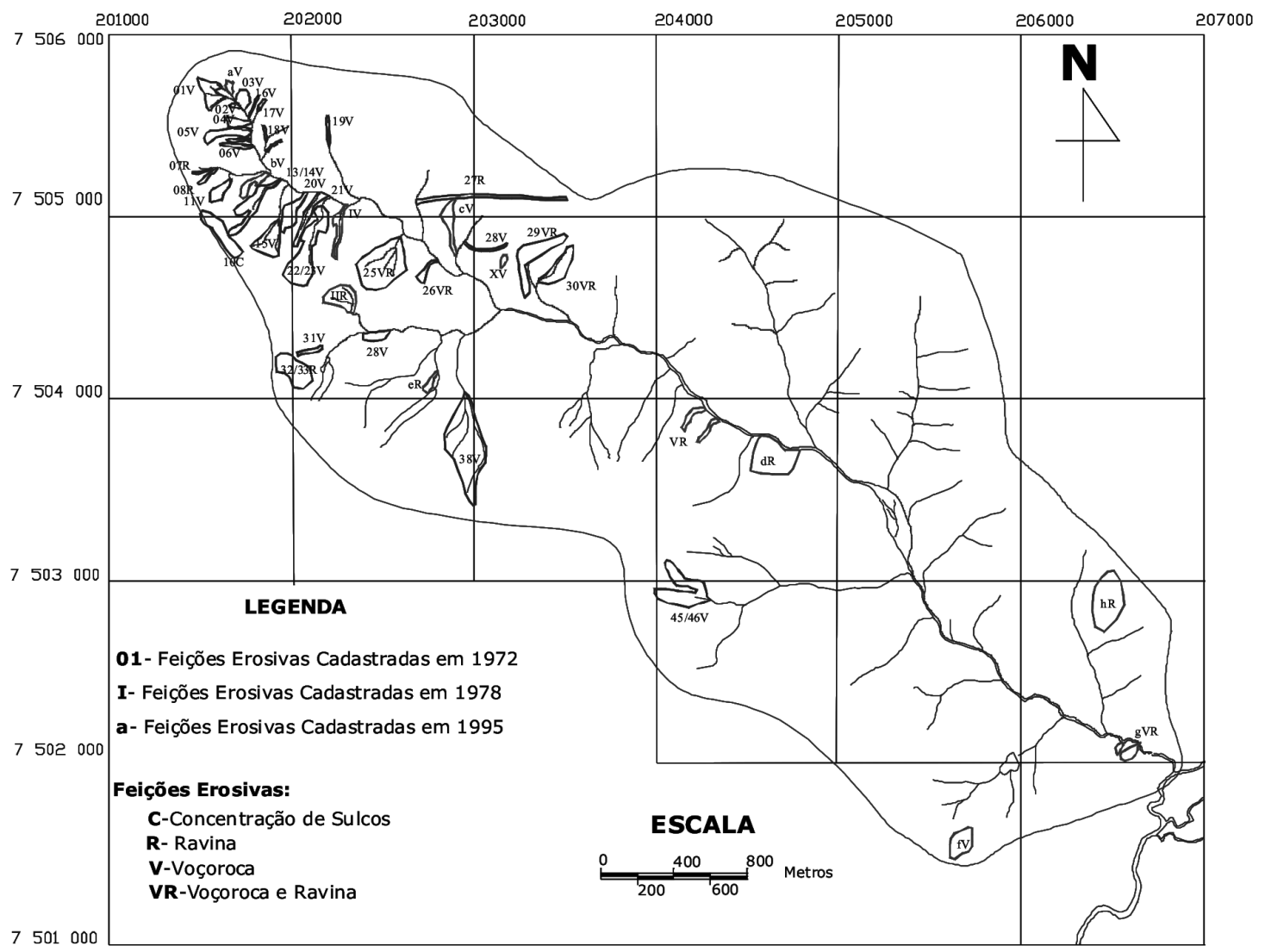

Figura 8 - Mapa das feições erosivas do ano de 1995.

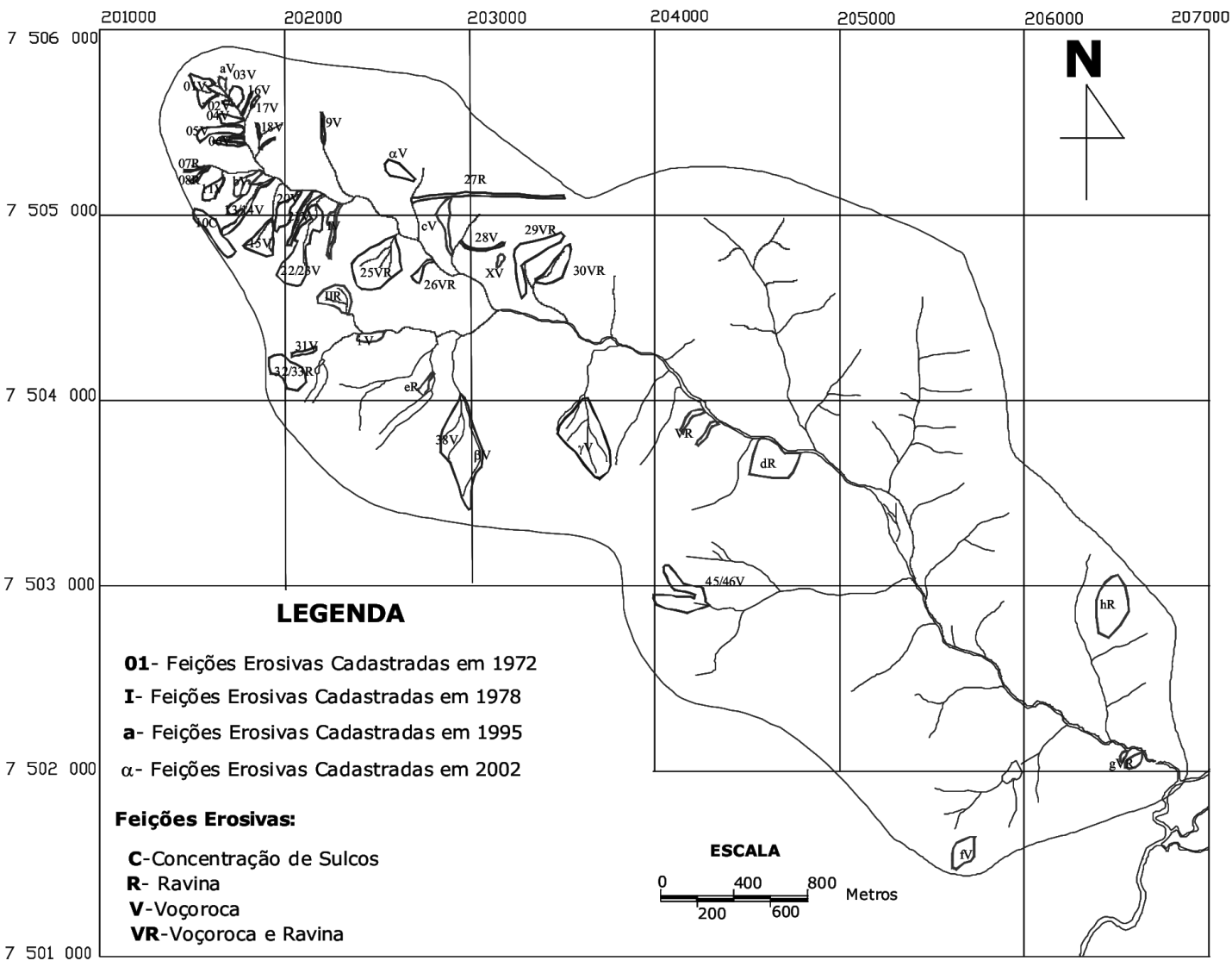

Figura 9 - Mapa das feições erosivas do ano 2002. 
ano o número de voçorocas aumentou, sendo estas as feições $20,21,31$ e 38 . As voçorocas 13 e 14 , e 22 e 23 e 32 e 33, uniram-se formando grandes feições erosivas. As feições 26,29 e 30, que eram respectivamente do tipo concentração de sulcos $(\mathrm{C})$, voçorocas $(\mathrm{V})$ e ravinas (R) evoluíram para ocorrência de voçorocas e ravinas (VR).

Outra mudança que ocorreu nas encostas da bacia do Espraiado foi o tipo de ocupação do solo; onde antes eram pastagens e fazendas, a fotografia de 1995 mostrou serem loteamentos residenciais. Levando em conta que a maioria das feições que evoluíram para voçorocas se encontravam localizadas próximo de áreas de loteamento residencial, como as $26 \mathrm{VR}, 29 \mathrm{VR}, 30 \mathrm{VR}$, $31 \mathrm{~V}, 32 / 33 \mathrm{~V}$ e $38 \mathrm{~V}$, conclui-se que este tipo ocupação influenciou a aceleração dos processos erosivos.

Na situação do ano de 1995, foram cadastradas 9 novas feições, sendo 5 voçorocas, 3 ravinas e 1 ocorrência de voçoroca e ravina, localizadas na parte intermediária-inferior das encostas, em encostas retilíneas íngremes, retilíneas-retilíneas, e côncavas-côncavas.

As feições eR e iV ficam localizadas em loteamentos residenciais, o que deixa concluir também a influencia da ocupação e uso do solo na ativação dos processos erosivos.

Situação em 2002 O mapa e o cadastro das feições erosivas do ano de 2002, que se apresenta na figura 9, foi elaborado a partir de trabalho de campo para confirmar as feições identificadas nas fotografias aéreas de 1995 e cadastrar as novas feições. Em 2002 foram confirmadas as registradas em 1995, e cadastradas 3 novas feições, todas do tipo voçorocas, localizadas na porção superior-intermediária das encostas. $\mathrm{O}$ que mais chamou a atenção foi a localização de duas destas feições, $\beta \mathrm{V}$ e $\gamma \mathrm{V}$, por se encontrarem em áreas que haviam sido reabilitadas, como mostra as Figuras. 10 e 11. A voçoroca $\alpha \mathrm{V}$ localizava-se numa área de pastagem como mostra a figura12.

Em 2002 foram cadastradas feições erosivas em estradas vicinais não pavimentadas que dão acesso a fazendas, de que são exemplos as Figuras. 13 e 14, mas estas feições não foram colocadas nos mapas, pois

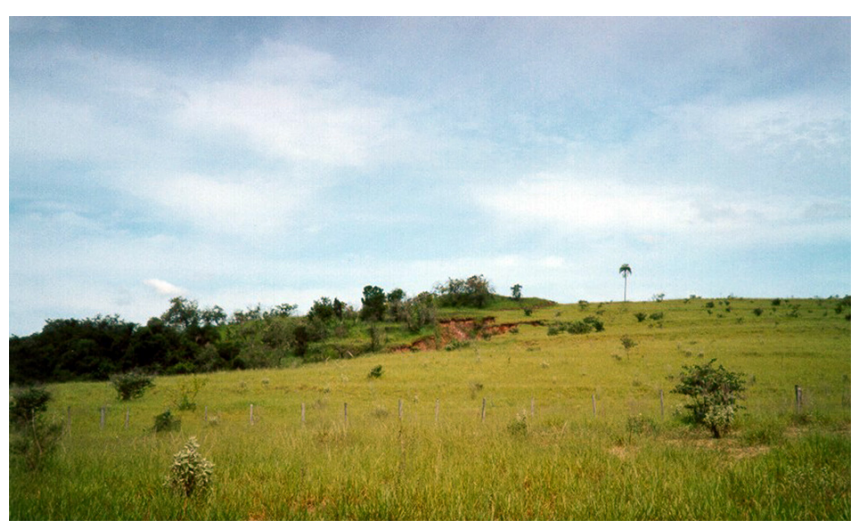

Figura 12 - Feição aV localizada na fazenda Santa Alice.
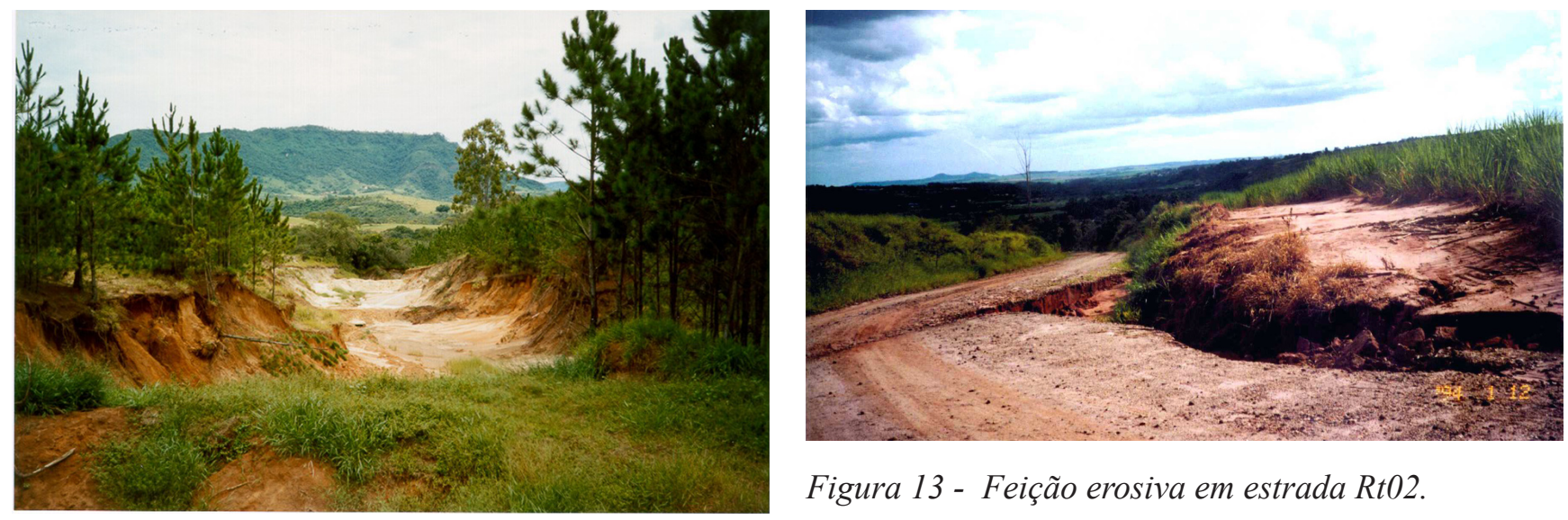

Figura 13 - Feição erosiva em estrada Rt02.

Figura 10 - Feição $\beta$ V localizada na Ar Rb 4. 


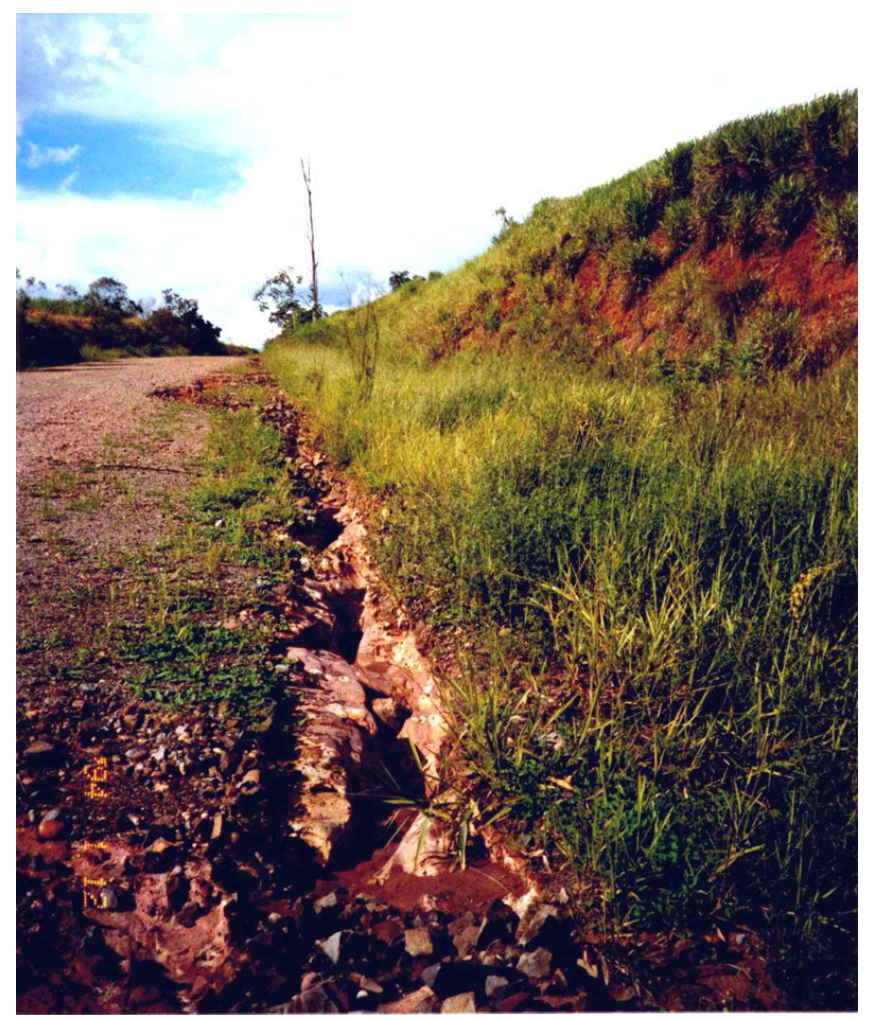

Figura 14 - Feição erosiva na estrada vicinal em rocha pouco alterada.

surgiam e eram logo eram aterradas. A estrada de acesso das fazendas à rodovia SP-191, que se localiza no divisor de águas entre as bacias do córrego do Espraiado e do Capim Fino, era a que apresentava maior número de feições erosivas, devido ao intenso tráfego de caminhões pesados e a sua localização na encosta, na porção intermediária-inferior da encosta retilínea.

Outro tipo de feição erosiva referia-se à erosão marginal que ocorria ao longo de todo o córrego do Espraiado, ocasionando o seu assoreamento como mostra a figura 15. Geralmente a ocorrência de erosão marginal é natural de drenagens, mas o que se percebe no córrego do Espraiado é a aceleração desse processo

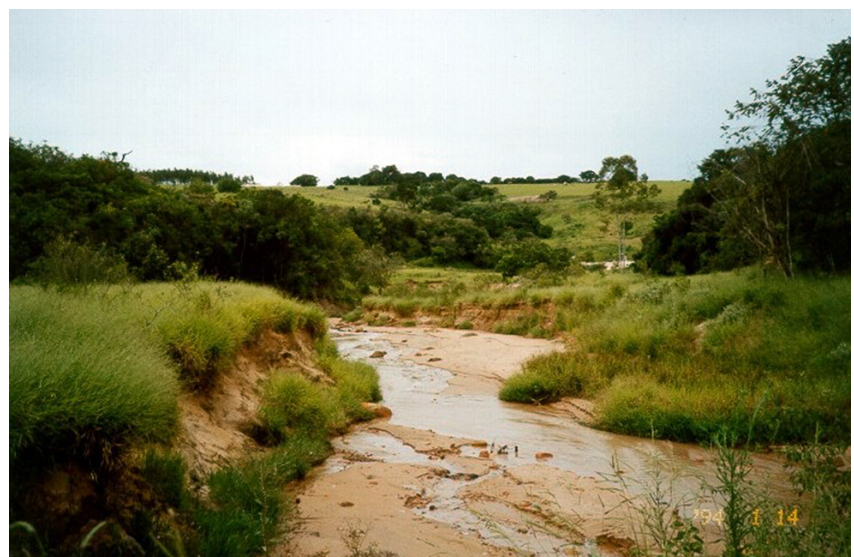

Figura 15 - Erosão marginal do córrego do Espraiado e seu assoreamento. como conseqüência da extração de areia do leito e das margens do córrego.

Estes exemplos, bem como outros já anteriormente referidos, corroboram a influencia da ação antrópica na ativação ou aceleração do fenômeno erosivo.

CONCLUSÕES O substrato rochoso na bacia do córrego do Espraiado, junto da cidade de São Pedro (SP) e litologicamente constituído por arenitos da Formação Pirambóia, de idade cretácico-jurassica que por sua vez dão origem a materiais inconsolidados que neste trabalho foram integrados em dois grupos: materiais inconsolidados residuais e materiais inconsolidados retrabalhados.

O principal problema ambiental que ocorre na área resulta da intensa erosão pluvial que afeta aqueles materiais.

Verifica-se que o numero maior de feições erosivas se situa na margem direita do córrego onde as encostas são geralmente retilíneas na parte superior e côncava no terço intermédio inferior. Na margem esquerda as encostas são côncavas na parte superior e convexa na parte intermédia inferior.

Os materiais inconsolidados são de tipo arenoso, mostrando os retrabalhados uma percentagem um pouco superior de argila. Deles foram constituídas 21 unidades sendo 12 de materiais inconsolidados residuais, 8 de retrabalhados, definindo-se ainda uma unidade de aluvião.

Quer os materiais inconsolidados residuais quer os retrabalhados são facilmente erodíveis. Este fato foi observado através da aplicação do índice de erodibilidade proposto por Nogami \& Villibor (1979), mas principalmente através da sua modificação proposta por Pejon (1992) e confirmado pelas observações no terreno.

As feições erosivas presentes são do tipo concentração de sulcos $(\mathrm{C})$, ravinas $(\mathrm{R})$, voçorocas $(\mathrm{V})$, concentração de sulcos e ravinas (CR) e associações de voçorocas e ravinas (VR). Foram identificadas e cadastradas as feições erosivas em quatro situações distintas no período entre 1972 e 2002 bem como a sua evolução com referencia as datas de 1972, 1978, 1995 e 2002.

A maioria das feições cadastradas no período abrangido pelo estudo foi identificada como já existente em 1972. A partir de então o estudo permitiu concluir que a erosão pluvial se continuou a fazer sentir de modo significativo. Ao longo do período abrangido pelo estudo foi detectado o surgimento de novas feições e registrada a evolução de feições pré-existentes para feições erosivas mais evoluídas, significando a irreversibilidade do processo e conduzindo a degradação das áreas de incidência do fenômeno erosivo.

Verificou-se que as feições de grande porte identificadas na bacia do Espraiado não interceptaram o nível freático, condição imposta por alguns autores para atribuição da designação voçoroca. No entanto considera-se ajustado utilizar essa designação por critério de dimensão, como se explica no texto.

Ficou comprovada a influencia da ação antrópica no ativar e acelerar do fenômeno erosivo que a maior 
evolução no processo se verificou em seqüência de intervenção antrópica ligada a operações de loteamento.

Do que fica exposto se conclui que se torna imprescindível considerar este tipo de estudos em qualquer política criteriosa de planejamento do uso do solo na área em análise bem como em qualquer outra em situação semelhante. Só assim se poderão evitar ou minimizar impactos derivados da degradação das áreas susceptíveis à erosão bem como situações de risco de perdas econômicas. Preservar deverá sempre prevalecer sobre recuperar.

\section{Referências}

Alcântara M.A.T 1997. Estudos da erodibilidade de alguns solos do estado de São Paulo. Dissertação de Mestrado, EESC/USP, 129p.

ABNT Associação Brasileira de Normas Técnicas. 1989. NBR-10703/89: Degradação do Solo;terminologia. São Paulo, SP.

Blum W.E.H. 1997. Basic concepts: degradation, resilience, and rehabilitation. In: R. Lal, W.E.H. Blum, C. Valentin, B.A. Stewart (eds.) Methods for assessment of soil degradation. Boca Raton, CRC Press, p.1-16.

Canil K., Iwasa O.Y., Silva W.S., Almeida L.E.G. 1995. Mapa de feições erosivas lineares do estado de São Paulo: Uma análise qualitativa e quantitativa. In: ABGE/UNES, Simpósio Nacional de Controle de Erosão, 5, Bauru, atas, v.5, p. 249-251.

Facincani E.M. 1995a. Influência da estrutura e tectônica no desenvolvimento das boçorocas da região de São Pedro, SP: proposta de reabilitação e aspectos jurídicos- institucionais correlatos. Rio Claro, Dissertação Mestrado, Universidade Estadual Paulista, $124 \mathrm{p}$.

Facincani E.M., Cavalheiro F. 1995b. Boçorocas: aspectos da reabilitação por revegetação de São Pedro. Boletim de Geociências (Rio Claro), 14(4):268-275.

IPT Instituto de Tecnologias do Estado de São Paulo. 1989. Controle de Erosão: Bases Conceituais e Técnicas, Diretrizes para o Planejamento Urbano e Regional. Orientação para o Controle de Boçorocas Urbanas. São Paulo, Instituto de Pesquisas Tecnológicas, 2v., 230p.

IPT Instituto de Tecnologias do Estado de São Paulo. 1991. Orientações para o combate à erosão no Estado de São Paulo - Bacia do Médio Tietê. São Paulo, Convênio DAEE/IPT, 3v., 350p.

IPT Instituto de Tecnologias do Estado de São Paulo. 1993. Diagnóstico e recomendações sobre a boçoroca do Córrego Tucum, município de São Pedro, SP. São Paulo, $105 \mathrm{p}$.

Kopezinski I. 1998. Avaliação da degradação ambiental produzida por mineração no município de Poços de Caldas $(M G)$ considerando procedimentos de mapeamento geotécnico. São Carlos, Dissertação de Mestrado, Escola de Engenharia de São Carlos, Universidade de São Paulo, $193 \mathrm{p}$.

Köppen W. 1948. Climatologia con un estudo de los climas de la Tierra, Version Hendriches, P.R. México, Fondo de
Cultura Economica, 478 p.

Morgan R.P.C. 1996. Soil erosion and conservation. $2^{\text {nd }}$ ed. New York, Wiley; Harlow Essex England, Longman, 198p.

Morgan R.P.C., Rickson R.J. (ed.) (1995). Slope stabilization and erosion control: a bioengineering approach. London, E \& Fn Spon, 274p.

Nogamil J.S., Villibor D.F. 1979. Soil characterization of mapping units for highway purposes in a tropical area. Bulletin IAEG ( Krefeld-Germany), 19:196-199.

Pejon O.L. 1992. Mapeamento geotécnico de Piracicaba, Escala 1:100.000: estudo de aspectos metodológicos, de caracterização e de apresentação dos atributos. São Carlos, Tese de Doutoramento, Escola de Engenharia de São Carlos, Universidade de São Paulo.

Pejon O.J., Zuquette L.V. 1999. Avaliação de metodologia utilizado para elaboração de cartas de risco potencial a erosão acelerada - área de São Pedro. Sociedade \& Natureza (Uberlândia), 10(19):79-91.

Ponçano W.L., Prandini F.L. 1987. Boçorocas no Estado de São Paulo: Uma revisão. In: Simpósio Nacional de Controle de Erosão, 4, Marília/SP, Anais, p. 149-175.

Rodrigues-Carvalho J.A., Silva A.P. da, Cavaleiro V.M.P. 2004. Cartografia geotécnica e ambiental em Portugal. In: ABGE, Simpósio Brasileiro de Cartografia Geotécnica e Geoambiental, 5, São Carlos, vol. 1, p. 465-482.

Silva T.R.M. \& Lacerda W. 2001. Erodibilidade dos solos de uma voçoroca da região de Ouro Preto, Minas Gerais. In: ABGE, Simpósio Nacional de Controle de Erosão, 7, Goiânia/Go, Anais, CD Room.

Vertamatti E. \& Araújo F.A.R de. 1990. Critérios para previsão do potencial erosivo dos solos tropicais. In: Reunião Anual de Pavimentação, 24, Belém, p. 327-347.

Zuquette L.V. \& Nakazawa V.A. 1997. Cartas e mapas de geologia de engenharia. In: ABGE (ed.) Geologia de Engenharia. São Paulo, Editora, cap.17, p. 283-300.

Wichschmeier W.H. (1971). A soil erodibility nomograph for farmland and construction sites. J. Soil Water Conserv., 26:189-193.

Manuscrito ID 8311

Submetido em 19 de julho de 2007

Aceito em 11 de dezembro de 2007 Sistema eletrônico de submissão 